\title{
CONSIDERAÇÕES SOBRE A PROSPERIDADE PERFEITA
}

\section{APPRECIATIONS ON A PERFECT PROSPERITY}

\section{APPRECIATIONS ON A PERFECT PROSPERITY}

\section{PROF. DR. ANTONIO LOPES DE SÁ}

Doutor em Ciências Contábeis pela Universidade do Brasil, Detentor da Medalha João Lyra Tavares, Presidente da Associação Cientifica Internacional de Contabilidade e Economia, $1^{\circ}$ Vice-Presidente da Academia Brasileira de Ciências Contábeis, Vice-Presidente da Academia Nacional de Economia, membro da Real Academia de Ciencias Economicas e Financieras da Espanha, membro da Academie des Sciences Commerciales de Paris e do International research Institute de New Jersey USA

lopessa.bhz@terra.com.br

\section{RESUMO}

Finalidade dos empreendimentos é atingir um estado em que o patrimônio possa render a maior utilidade e o seu crescimento operar-se como algo racional, natural e constante.

É a eficácia permanente que leva as células sociais (empresas e instituições) a progredirem sempre, ou seja, a se dilatarem pelos seus recursos próprios. O fenômeno da prosperidade, todavia, só sucede quando a interação dos sistemas de funções patrimoniais ocorre de forma perfeita. Interações perfeitas exigem que todos os sistemas de funções reciprocamente se ajudem no processo da plena satisfação das necessidades.

Palavras-chave: Prosperidade. Crescimento Empresarial. Eficácia. Finalidade Empresarial. Lucros Constantes.

\section{ABSTRACT}

The enterprises' purpose is to reach a condition where it's patrimony can pay its best expedience and its growth can work as reasonable, natural and regular as possible. 
It's the constant Effectiveness that takes the social cells (companies and institutions) to always improve, in other words, to enlarge on it's own means. The prosperity phenomenon, nevertheless, only takes place when interaction of the patrimony function systems occurs perfectly. Perfect interactions demand that all function systems help each other mutually in the process of absolutely fulfilling the needs.

Keywords: Prosperity. Company Growth. Efficacy. Enterprises' purpose. Constant Profit.

\section{RESUMEN}

La finalidad de las iniciativas es alcanzar un estado en que el patrimonio pueda rendir la mayor utilidad y su crecimiento operarse como algo racional, natural y constante.

Es la eficacia permanente que lleva las células sociales (empresas e instituciones) a progresar siempre, o sea, a dilatarse por sus recursos propios. El fenómeno de la prosperidad, por ahora, sólo deviene cuando la interacción de los sistemas de funciones patrimoniales ocurre de forma perfecta. Interacciones perfectas exigen que todos los sistemas de funciones recíprocamente se ayuden en el proceso de la plena satisfacción de las necesidades.

Palabras-Clave: Prosperidad. Crecimiento Empresarial. Eficacia. Finalidad Empresarial. Ganancias Constantes.

\section{ELEMENTOS DA PROSPERIDADE}

Finalidade no estudo científico da Contabilidade é exatamente ter sempre em observação o desempenho sobre o aproveitamento adequado da riqueza, esta como provedora das necessidades diversas que a vida dos empreendimentos suscita.

Cumprir o propósito pelo qual se forma um patrimônio é, pois, não só o desejável, mas, também, preocupação de estudos específicos.

No campo científico a meta deve ser a da construção de proposições lógicas que possam sustentar teorias cujas aplicações resultem na produção de modelos que orientem metas de plena capacidade de realização dos objetivos empresariais e institucionais.

Considerar $(E a \rightarrow \infty)(E l \rightarrow \infty) \Rightarrow P$ s ıadamente a consecução do seu escopo uma célula social (empresa ou instituição) que cresce de forma conseqüente, o objetivo passa a ser o da conquista da Prosperidade.

Sob a ótica referida, todavia, é preciso ter em mente que o importante para a riqueza não é apenas dimensionar-se em maior volume, mas conseguir uma ampliação de natureza racional. 


\section{repec}

Portanto, não se deve entender apenas o aumento do patrimônio como uma prova de bom comportamento dele.

Necessário é admitir que o escopo deva estar em alcançar uma situação específica que se caracteriza pela pujança constante capaz de determinar um crescimento coerente.

Por Prosperidade, pois, deve ser entendida a constância da eficácia com a ocorrência simultânea do aumento da elasticidade como crescimento da célula social, dentro de uma condição de plena racionalidade.

Três são, portanto, os elementos a serem considerados na ocorrência do referido fenômeno: eficácia, constância da eficácia e crescimento racional do patrimônio (Elasticidade crescente).

Ou seja:

Portanto, a eficácia (Ea), existindo indefinidamente, para o que se tem também indefinidamente uma elasticidade crescente (EI), implica logicamente Prosperidade (Ps).

Se uma empresa se comportar harmoniosamente em todas as suas oito funções patrimoniais (liquidez, resultabilidade, estabilidade, economicidade, produtividade, invulnerabilidade, elasticidade e socialidade), ajudando-se umas às outras, poderá não só garantir a continuidade como também a ampliação de utilidade patrimonial.

Se tiver o empreendimento capacidade de: pagar em dia, conseguir lucros adequados, manter-se em equilíbrio com circulação vital e sem desperdiçar, cobrir seus riscos, crescer, viver em harmonia com os seus ambientes, logicamente reunirá todas as condições para um estado de Prosperidade.

Assim, por exemplo: se o lucro ajuda a aumentar a liquidez e se a liquidez volta a ajudar a aumentar o lucro; se a produtividade ajuda a lucratividade e se esta ajuda aquela, e, assim por diante, estarão sempre ocorrendo Interações Perfeitas.

O conceito de "perfeição", no caso, coaduna-se com o que seja factível dentro do que é requerido pelas necessidader ${ }_{P S}^{-1} \ldots I P S_{1}^{8}$ ?quado desempenho da riqueza.

Tal conceito visa a expressa d exısıeı ıcia de reciprocidades de eficácias, ou seja, quando os bens patrimoniais, como utilidades, não se limitam a uma só natureza de função eficaz, mas, também, a outras, a tudo satisfazendo.

Assim, por exemplo, os investimentos em matérias-primas não devem satisfazer apenas a necessidade de obter lucro com um produto, mas, igualmente, de trazer pelo seu giro a capacidade de pagamento, sem permitir desequilíbrios por excesso ou escassez de aplicação, sem ensejar desperdícios etc.

Deveras importante, portanto, não é apenas fazer crescer em volume o patrimônio, eventualmente, mas crescer conjuntural e harmoniosamente sempre.

O estudo analítico de uma empresa deve abranger, pois, todas as funções que os 
elementos da riqueza devem cumprir, observando se nesse critério de recíproco proveito existe um "crescimento" racional.

Disso deflui o teorema da "Dependência Funcional":

A ocorrência do estado peculiar de prosperidade depende de Interações Perfeitas entre os Sistemas de Funções Patrimoniais.

Ou seja, haverá Prosperidade (Ps) se - e somente se - houver Interações Perfeitas entre os sistemas patrimoniais (IPS), ou seja, em todos os oito existentes.

Tal propósito parece ser o que as células sociais pretendem buscar, até o limite do possível.

Isso porque tudo se passa como se existisse um ponto de saturação de crescimento, ou seja, um estado dimensional de expansão que, ultrapassado, determinaria o crescimento inconveniente.

A elasticidade progressiva tende a ocorrer, pois, até a fronteira do factível condicionada aos efeitos de natureza de espaço e tempo.

O tamanho conveniente de uma célula social é uma condição de racionalidade e oferece matéria para um estudo específico, merecendo considerações que envolvem a apreciação de um número expressivo de variáveis.

\section{ASPECTOS DA PROSPERIDADE E DA POTENCIALIDADE}

A constituição de um patrimônio tem por escopo reunir elementos úteis para a satisfação das necessidades, ou seja, visa ao poder de utilidade.

"Potencialidade patrimonial", pois, é tudo o que se pode obter de proveito de uma riqueza em relação ao tempo e ao espaço.

A capacidade de um bem em gerar lucro é uma potencialidade como o é aquela de ensejar maior liquidez.

A eficácia real deriva-se desse poder referido, representando a anulação da necessidade que se materializa pela função ou uso do patrimônio.

É, portanto, "eficácia virtual" aquela que se reconhece pela "probabilidade de materialização" ou de "uso competente" da riqueza, permitindo a conceituação de "Potencialidade Patrimonial".

Quando existe ou se aumenta a "capacidade funcional", promove-se o estado potencial de um ou mais elementos de um patrimônio.

"Potencialidade Patrimonial" é, pois, a força de utilidade que a riqueza possui estaticamente, pelo fato de ter-se constituído com sanidade funcional (onde ocorre existência de utilidade) ou até com a intenção de que esta venha a ocorrer. 
É preciso admitir, portanto, que tal fenômeno tanto pode ser considerado em relação ao presente como ao futuro, mas sempre sob a ótica da "real capacidade de satisfazer necessidades".

Isso enseja, pelas razões que encerra, o teorema da "Natureza Eficaz":

Uma função que não só satisfaz a necessidade presente, mas que pode ensejar utilidade futura, tem o poder natural de ser relativamente eficaz.

Assim, por exemplo, uma fábrica pode ser construída para produzir 1.000.000 de unidades por mês, embora, em sua fase inicial, não alcance 500.000 unidades.

A capacidade instalada visa, no caso exemplificado, a ensejar continuidade produtiva sem problemas em relação a um futuro próximo, ainda que no presente exista ociosidade, mas permanecendo a confiança nas perspectivas acenadas pelo mercado.

Quando as previsões de expansão implicam investimentos imediatos visando ao futuro, mas sem a correspondência em rédito presente, ocorre a potencialidade, mas a eficácia é relativa.

A relatividade referida é a de uma necessidade apenas derivada de prospecção e não de efetivação de resultados proporcionais à aplicação realizada em meios de produção.

Não são poucas as empresas que, prevendo expansão, se superdimensionam nos seus imobilizados técnicos e até nas suas existências de mercadorias.

Ocorre, no caso, um superinvestimento calculado, ou seja, uma aplicação além do utilizável nos primeiros anos, mas previsível para tempos posteriores nos quais as instalações precisarão estar competentemente preparadas para enfrentarem uma previsível e confiável demanda do mercado consumidor.

Algumas vezes tais fatos são gerados em decorrência de pretender-se ensejar uma continuidade sem atropelos, ainda que assumindo o risco calculado de ociosidade temporária.

Isso implica cautela sobre a falibilidade das previsões, a qual se manifesta não raramente quando faltam técnica e sensibilidade sobre a realidade dos mercados.

Os erros por superinvestimentos, derivados quase sempre de planejamento inadequado, tendem a gerar a ociosidade, que é fator de perdas, sendo, neste caso, imprópria a consideração de "potencialidade" pela falta da qualidade de emprego.

É preciso que se associem força de utilidade e probabilidade de ocorrência de utilização para que uma potencialidade possa ser considerada como fenômeno patrimonial.

Os erros de previsão quase sempre defluem de prospecções apenas intuitivas ou pragmáticas, sem bases em estudos competentes dos ambientes internos e externos em relação à empresa ou instituição.

Ocorre ainda que um empreendimento, mesmo relativamente próspero, possa deixar de utilizar toda a sua potencialidade de produção. 
O relativo, no caso referido, está em que ocorre prosperidade, mas sem que seja a Prosperidade Perfeita.

Também podem suceder casos em que exista o uso de toda a capacidade patrimonial instalada, mas que não venha a existir Prosperidade.

A correlação, pois, entre a potencialidade patrimonial e a prosperidade comporta variadas condições, mas aquela "perfeita" só se dá quando "todos os sistemas de um patrimônio possuem Interação Perfeita".

A empresa que se superdimensiona, ganhando grande possibilidade de uso, maior que aquela requerida em um dado momento, não tem vedada a prosperidade naquilo que consegue aproveitar, mas pode suportar ônus adicional nem sempre calculado.

O fenômeno do crescimento operacional, mesmo com ociosidade de parte do imobilizado técnico, é algo possível e verificável na prática.

Pode-se prever a ociosidade temporária de um superinvestimento, mas com garantia futura de sobrevivência, nesse caso ocorrendo apenas um desequilíbrio estático.

Vários são os negócios que se iniciam em um determinado ponto comercial, adquirem grande sucesso e depois estacionam porque não possuem mais espaço para abrigar a expansão.

Por isto algumas empresas vão prosperando, sem, todavia, utilizarem tudo o que foi objeto de investimento inicial.

Tais empreendimentos crescem, mas mantêm desde o início, por exemplo, o imobilizado já grande, excessivo, conservando a potencialidade do que só mais tarde será utilizado.

Ocorre, no caso, uma desigualdade entre a potencialidade dos meios patrimoniais e aquela das necessidades de se realizar a plena utilização e a conseqüente prosperidade pertinente.

Quando, todavia, há uma equivalência entre as duas potencialidades (necessidades e meios), ocorrerá a Prosperidade Perfeita, mas se, e somente se, as interações das funções sistemáticas dos meios patrimoniais forem também perfeitas.

Se a empresa está operando com toda a sua capacidade instalada e, se isto se realiza com a interação perfeita entre os sistemas de funções patrimoniais, repito, naturalmente, a Prosperidade alcança o seu estado de perfeição.

Nem sempre isso é possível, mas tal situação é uma realidade que se encontra na prática, ou seja, é um estado verificável do comportamento da riqueza das células sociais.

Se as potencialidades de necessidades crescem e as potencialidades de meios patrimoniais também, a prosperidade tenderá a ser considerada como "perfeita".

Logo, enquanto uma empresa for superdimensionada ou subdimensionada, não terá por si só uma Prosperidade Perfeita, embora possa estar em estado de "Prosperidade Relativa".

São aspectos conceituais que não se confundem.

Atingido o limite de potencialidade dos meios, todavia, prosseguindo a empresa a cres- 
cer em meios compatíveis com as suas necessidades e possibilidades, a situação atingirá seu nível de adequação, promovendo a Perfeição (esta equivalendo à adequação racional).

Isto nos sugere a observação permanente entre os aspectos de potencialidades.

Uma empresa também pode ser próspera, sem, todavia, explorar toda a sua capacidade de abranger o mercado.

Pode ser próspera, mas não tanto quanto poderia alcançar se dispusesse de meios patrimoniais.

Nesse caso a potencialidade das necessidades se manifesta como maior que aquela dos meios instalados.

Isso ocorre em muitas empresas menores que trabalham com alto padrão de qualidade.

Possuem as referidas empresas muitos clientes, recebem copiosos pedidos, mas não têm produtos suficientes para entregar e nem condições de ampliar a produção porque dependem de financiamento expressivo (no Brasil, oneroso em razão da abusiva taxa de juros).

O óbice do crédito mal dimensionado, do alto custo deste, é um grave mal, abominado de há muito por grandes e famosos industriais, como Henry Ford, em sua obra Os princípios da prosperidade, e até por intelectuais de valor como Albert Einstein em Como vejo o mundo.

Muitíssimos são os casos em que só uma associação com empresas mais fortes pode resolver a questão da potencialidade, mas, quase sempre, com perda da liberdade de comando dos antigos proprietários.

É uma situação inversa da primeira exemplificada, mas que também não oferece condições de ocorrência da Potencialidade Perfeita.

A mensuração, o estudo, dessas "Potencialidades", em face da "Prosperidade", é responsabilidade dos profissionais da Contabilidade, e só o conhecimento doutrinário, científico, oferece condições para que se possam apontar as diretrizes a serem tomadas pelos empresários.

\section{O TEOREMA DA PROSPERIDADE PERFEITA}

Diante do exposto, é permitido coletar observações, percepções e conceitos, e reuni-los para uma proposição lógica.

Tal proposição, no caso o "Teorema da Prosperidade Perfeita”, assim se enuncia:

Quando a elasticidade constante se opera com equivalência entre as potencialidades das necessidades e a dos meios patrimoniais das células sociais, em um regime de interação perfeita entre os sistemas de funções, ocorre a Prosperidade Perfeita.

Como corolário, pode-se enunciar: 
A ocorrência de equivalência entre potencialidades de necessidades e meios patrimoniais tenderá sempre a manter-se, quando as interações se mantiverem também perfeitas.

Se uma empresa está expandindo com harmonia e tem meios para suprir tal expansão, tudo estará bem coordenado, mas dependerá de que as funções não percam a força interagente.

É possível, em dialética matemática, expressar o Teorema da Prosperidade Perfeita da seguinte forma:

Ou seja: Haverá Prosperidade Perfeita (PsP), se - e somente se - as necessidades patrimoniais potenciais $(\mathrm{PnP})$ equivalerem aos meios patrimoniais potenciais $(\mathrm{PmP})$, para o que também se tem a Interação Perfeita (IP), implicando esta, logicamente, eficácia (Ea) constante e em decorrência, logo, a Elasticidade (El), também, constante.

É possível detectar todos esses fenômenos por meio de registros contábeis especiais e de uma análise realizada por sistemas de funções patrimoniais (o que sugere um plano específico).

A informação contábil é mero instrumento que, para ter plena utilidade, necessita de capacidade de entendimento, o qual compete à doutrina científica suprir porque só ela pode oferecer conclusões racionais sobre a realidade do comportamento da riqueza na perseguição da Prosperidade.

\section{TEMPORALIDADE E MATURIDADE}

A eficácia da potencialidade patrimonial depende de fatores diversos, entre eles o tempo.

Como o capital tem vocação dinâmica e só mediante esta pode aspirar ao rédito, sendo este o que enseja o crescimento, imprescindível é considerar o prazo em que a utilidade pertinente se completa.

Ou seja, importante é conhecer o limite de tempo requerido para que o patrimônio possa satisfazer aos propósitos dos empreendimentos.

Isso se fundamenta no teorema que enuncia as razões lógicas entre a "maturidade" (quando se completa a utilidade) e a velocidade ou giro da riqueza (que se realiza em um tempo determinado), ou seja:

O prazo de maturidade da função condiciona-se àquele em que se opera a velocidade do meio patrimonial até a completa satisfação da necessidade pertinente. 
Quando um elemento do patrimônio precisa de prazo longo para que possa completar a sua utilidade, certamente requer, para isso, recursos competentes.

Se a empresa sustenta com capital próprio o investimento, poderá estar livre de descapitalizar-se ou de criar custos elevados derivados de empréstimos ou financiamentos, mas dependerá diretamente da maturidade da utilidade das funções no que investiu ou aplicou; isso enseja outro teorema:

Há uma razão inversa entre a velocidade do giro das aplicações e o quantitativo dos recursos próprios do empreendimento.

Isso significa que, quanto mais rápido girar o capital aplicado, menos necessidade de capital próprio existirá.

Assim, ao inverso, mais capital próprio tende a requerer uma empresa que precise de imobilizações de maior vulto.

A maturidade da utilidade, pois, tem muito a ver com essa agilidade, tal como a tem a eficácia defluente.

Ou seja, a forma de se financiar o que se utiliza, sob a ótica da prosperidade, requer que se respeite a correlação entre o poder da fonte do capital e aquele do elemento patrimonial em função da utilidade do crescimento.

Investimento que possui retorno em longo prazo tende a necessitar de financiamento também em longo prazo, preferível sendo, para beneficiar o crescimento com réditos acumulados, que a fonte de recurso seja a própria ou da empresa.

Necessário ainda é considerar o risco inerente ao investimento de maior prazo quanto à maturidade da eficácia, a qual em nossos dias se vê constantemente ameaçada pelo fenômeno da obsolescência.

Maturidade longa de utilidade traz como aderente a incerteza sobre a integridade patrimonial e a eficácia do resultado.

Todos esses aspectos, pois, são imprescindíveis de serem observados quando o que se objetiva é produzir modelos contábeis para a orientação das decisões administrativas em direção da Prosperidade Perfeita.

\section{RELATIVIDADE E PROSPERIDADE PERFEITA}

A "Prosperidade Perfeita", tal como no neopatrimonialismo se admite, não é a de um estado absoluto de perfeição, mas daquele aceitável como desejável, adequado e alcançável dentro dos limites de necessidades definidas.

Isso porque o sentido absoluto parece ainda inalcançável no campo das ciências do homem. 
O preciosismo matemático pode, teoricamente, determinar o absoluto no abstrato, embora saibamos ser isso uma ficção, se estabelecermos comparações com a complexidade da existência.

O misticismo matemático, como o legado pitagórico, fornece uma idéia, proveniente do longínquo século $\mathrm{VI}$ antes de Cristo, daquilo que se busca sempre, além dos frios números.

Embora a prevalência da essência tenha sido a tônica de Pitágoras, seu misticismo (que também inspiraria cientistas modernos como Kepler), foi na realidade uma grande apologia do relativo.

Mais de 2.500 anos depois, a ciência de nossos dias abraça a Metafísica, mergulha na relatividade, afirma que esta é o caminho admissível e recomendável; tal conclusão, não faz muitos anos, foi a que defluiu da reunião de sábios cientistas em Veneza, em 1986, patrocinada pela Unesco.

Nada se tem, pois, manifestado tão relativo quanto o conceito de absoluto, por paradoxal que possa parecer, especialmente no campo das ciências.

A relatividade é praticamente axiomática, em termos de todos os atos dimanados do homem.

Tudo se passa como se houvesse sempre algo além que pudesse ter sido atingido e esse "mais" parece ainda perdido no campo das limitações de um estado a se definir como "perfeito".

Perfeito, então, passa a ser o melhor que pode ser conseguido em razão de circunstâncias existentes, ou seja, o factível racional.

O campo científico está sempre a apresentar surpresas e a reformar "verdades".

Há cerca de dez anos os astrônomos anunciaram que se equivocaram no que tangia à quantidade de galáxias e foi-lhes possível verificar cinco vezes mais o número que era admitido como certo.

Em 2.005 contestaram a quantidade de planetas no próprio sistema solar no qual a Terra se insere.

Mesmo diante de todas essas dúvidas, dessas que hoje envolvem também o micromundo no que tange às cadeias do DNA, quanto ainda existe a considerar-se com relatividade?

A incapacidade de observação do ser humano vai sendo vencida, a cada dia, pelo progresso material dos equipamentos de trabalho e pesquisa, mas novas conquistas não fazem, senão, comprovar a relatividade conceitual anterior e seu caráter evolutivo.

A expressão "Perfeita", como conceito, portanto, em Contabilidade, como aqui se utiliza, é equivalente ao que se fez desejável, permissível, satisfatório, ou, ainda, é conceitualmente uma "Perfeição Relativa".

Se atingirmos o possível no uso dos meios patrimoniais, para a satisfação de necessidades e, se o fizermos dentro do máximo de potencialidade alcançável nesta correlação necessidade/meios patrimoniais, não será de todo inadequado admitir-se tal estado, em sua relatividade, como Perfeito. 


\section{REFERÊNCIAS}

ABICALAFFE, César. A fórmula do sucesso empresarial e profissional. São Paulo: Editora Gente, 1995.

BARKER, Richard. "Reportes de desempeno financiero", em Revista Internacional Legis de Contabilidad \& Auditoria, n. ${ }^{\circ} 22$, Bogotá, Junho de 2005.

BENAU, Maria Antonia Garcia e MAYORAL, Juan Monterrey. "Analisis de la información previsional y cualitativa", II Jornada de Trabajo sobre Analisis Contable, edição ASEPUC, Malaga, setembro de 1995.

CASELLA, Carlos Luis Garcia e RAMIREZ, Maria Del Carmen Rodriguez de (coordenadores e equipe do Instituto de Investigaciones Contables Alberto Arevalo). Modelos Contables con metodo cientifico, edição Ediciones Cooperativas, projeto de pesquisa, Buenos Aires, 2001-2004.

FERREIRA, Rogério Fernandes. Opções - Estudos de Gestão. Lisboa: edição Editorial Noticias, 1994.

FORD, Henry. Os princípios da prosperidade. Rio de Janeiro: editora Brand, tradução de Monteiro Lobato, 1954.

HERRSCHER, Enrique G. La economia de las empresas. Buenos Aires: Editorial Galerna, 1992.

KOLLER, Tim e outros. Valuation - Measuring and managing the value of companies. New Jersey: edição Wiley, 2005.

NEGRA, Carlos Alberto Serra e NEGRA, Elizabete Marinho Serra. "A visão neopatrimonialista da entidade contábil: a célula social", em Revista de Contabilidade do Rio Grande do Sul, Porto Alegre, dezembro de 2004.

ONIDA, Pietro. La dimensioni del capitale di impresa. Milão: edição Giuffré, 2. a edição, 1944.

RIPARBELLI, Alberto. Il contributo della Ragioneria nell'analisi dei dissesti aziendali. Florença: edição Vallechi, 1950.

VIRGILITO, Benito Salvatore. Estatística Aplicada, Técnicas básicas e avançadas. São Paulo: editora Alfa Omega, 2005.

ZAPPA, Gino. II reddito di impresa. Milão: 2. ${ }^{a}$ edição, editor Giuffré, 1946.

ZURUTUZA, Emilio. "La empresa y el proceso de integración economico internacional”, em Internacionalización de la empresa: un desafio para el 2.000. Madri: edição AECA, 1995. 